\title{
Investigative Behavioral Intention to Knowledge Acceptance and Motivation in Cloud Computing Applications
}

\author{
Case study: Group of students from Jordanian universities
}

\author{
Sundus A. Hamoodi \\ Department of Business Networking and Systems Management \\ Philadelphia University \\ Amman -Jordan
}

\begin{abstract}
Recently the number of Cloud Computing users in educational institutions has increased. Students have the chance to access various applications and this gives the opportunity to take advantage of those applications. This study examined the behavioral Intention toward Cloud Computing Applications and evaluated the acceptance of these Applications. Participants population consisted of $\mathbf{1 1 0}$ students from different Jordanian universities. The results showed that Performance Expectancy, Effort Expectancy, Attitude toward using Technology, Social Influence, Self-Efficacy, Attention and Relevance have different levels of correlation with Behavioral Intention in Cloud Computing Applications, and there was no correlation between Anxiety and Behavioral Intention in Cloud Computing Applications.
\end{abstract}

Keywords-Cloud computing; formatting; ARCS model; UTAUT model

\section{INTRODUCTION}

Cloud Computing is considered as the most modern technique which can be used in education today in order to deliver services that can help students and learners to accomplish their tasks in an effective and efficient way.

Many researchers defined and described cloud computing in different ways. The researchers shared a number of facts about Cloud Computing that convert Information Technology from product to service. A number of researches clarified that "The cloud can provide exactly the same technologies as "traditional" IT infrastructure, the main difference, as mentioned previously, is that each of these technologies is provided as a service" [7]. Yuvaraj gave an example of Cloud Computing tools that may help users in different categories, "There are various cloud based tools for reference service needs of the libraries such as cloud-based video services (e.g. YouTube, TeacherTub), information collection services (e.g Google forms) and files sharing services (e.g. Dropbox)" [23].

Cloud Computing transfers the processing and storage to the cloud that saves more cost by providing more storage space, software license, and hardware device maintenance. Many features can be offered by Cloud Computing applications such as availability of the storage space that can be reached at any time at any place. According to Al Mourad and Hussain, "Cloud services deliver compute, storage, software, applications, etc. Via Internet to customers on a selfserve basic [4]. In addition, students and learners can accomplish their works and assignments through cloud computing applications that enable them to share their duties with professors and students if required. Researchers in Cloud Computing discuss many challenges related to this technique. The most important of these challenges are lack of privacy and security [16] [17].

Other researchers also explain the Cloud Computing concept and how companies and universities move toward Cloud Computing [1] [3] [10].However, few of them studied some of the factors which influence university students who use Cloud Computing applications in their study including homework assignment.

From previous studies, the researcher has identified several factors which may have influence on university students in using cloud Computer Applications.

The main objective of this paper is to examine the influence of these factors on students' performance and seeks to answer to the following questions:

- Can Jordanian students work with Cloud Computing Applications?

- Do Cloud Computing Applications motivate students to use them in their study?

- What are the main problems facing Jordanian students in using Cloud Computing Applications?

The researcher has also defined a set of hypothesis, developed a questionnaire, and formed an experimental group of students to work on Cloud Computing Applications. The findings from using SPSS analysis were discussed and interpreted the correlations between different factors and behavioral intention to use Cloud Computing Applications.

\section{PREVIOUS STUdIES}

Cloud Computing is one of the modern terminology which has recently received an increasing attention by researchers in both theory and applications. 
It was defined in several ways through its features and services that can be offered. According to U.S. National Institute of Standards and Technology (NIST), "Cloud computing is a model for enabling convenient on-demand network access to a shared pool of configurable computing resources (e.g., Networks, servers, storage, applications, and services) that can be rapidly provisioned and released with minimal management effort or service provider interaction "[15]. Hashemi and Seyyed explained that "Cloud computing is making the pool of virtual computing resources with a focus on large scale computing resources that are connected to the network and which allows customers to be shared dynamic hardware, software resources and data, and according to their actual usage, paying costs" [9].

Based on the literature studies, the researcher defines Cloud Computing as follows: Cloud Computing is a model of services that allowed users to access and use different virtual resources in an easy way and without the need to recognize how to maintain and manage those resources. below:

The characteristics of Cloud Computing are discussed

\section{A. On-demand access}

On-demand network access is sharing a pool of computing resources by different users from different places. Users can access shared resources at anytime and anywhere [3] [2] [22]. Karim discussed that "a wide range of end users have access to the applications and data served by the cloud" [10]. Cloud Computing resources grow on-demand which led to that various applications uses cloud technology now a day [18]. Further, its being illustrated that "Using this feature when needed the customer can easily and automatically access computing facilities like server, net, storage from any provider as soon as possible." [8]. Access to Cloud Computing may take different ways depending on the user needs.

According to the National Institute of Standards and Technology's (NIST), there are three ways to access a Cloud Computing: software as a service, platform as a service, and infrastructure as a service [15]. The demand on Cloud Computing increases due to the increased accessibility of the internet and its expansion using the digital devices [6].

In addition, other researchers discussed that using service models (Infrastructure, Platform and Software) are more flexible for education [1]. They encouraged to use Cloud Computing in education due to its features and the benefits it may result in such as; reduce cost of technology, enhance communications and give better service delivery. According to Adeoye, 2015 "Cloud computing is the better ICT utilization mechanism for educational institutions teaching, learning and a service delivery requirement, for it enables wise and strategic use of technology that significantly reduces the cost"[2].

\section{B. Ubiquitous network access}

Location-independent resource pooling: The resources needed by different customers can be supplied by providers which contain storage and memory frequency Internet and virtual systems as a pool feature [8].

\section{Data storage}

Storing information and data through Cloud Computing does not require large storage spaces on the user's laptop and smart devices. "Cloud Storage delivers virtualized storage on demand over a network based on a request for a given quality of service (QoS)" [19]. On demand storage could be delivered by cloud storage on a network that based on a given quality service. Further, Abu El-Ala stated that Cloud Computing "includes all the services related to the infrastructure of the cloud such as physical resources (as storage devices, school servers, and national communication network, etc.)" [2].

Users can reduce their costs by using the Cloud Computing which does not require an internal power to store information [19].

\section{Development and Maintenance}

One of the Cloud's Computing's benefits is that people and institutions are not responsible for updating and maintaining the applications and services. This means that they can save time and money for updating and maintenance needs. "User is not responsible for where the services or applications are located or how it maintained or updated") [3].

\section{UTAUT MODEL}

Unified Theory of Acceptance and Use of Technology Model (UTAUT) is a model of acceptance, formulated by Venkatesh and others, integrates theories and models to measure user's intention and usage of technology [21]. The dimensions of this model as discussed by different authors [20], [5] are as follows:

- Performance Expectancy: mark the individual expectancy on how much a system will help in improving job performance.

- Effort Expectancy: Less effort and ease of use of the technologies.

- Social Factors: How others believe about using technology.

- Facilitating conditions: Infrastructure required for supporting technologies to facilitate tasks. 


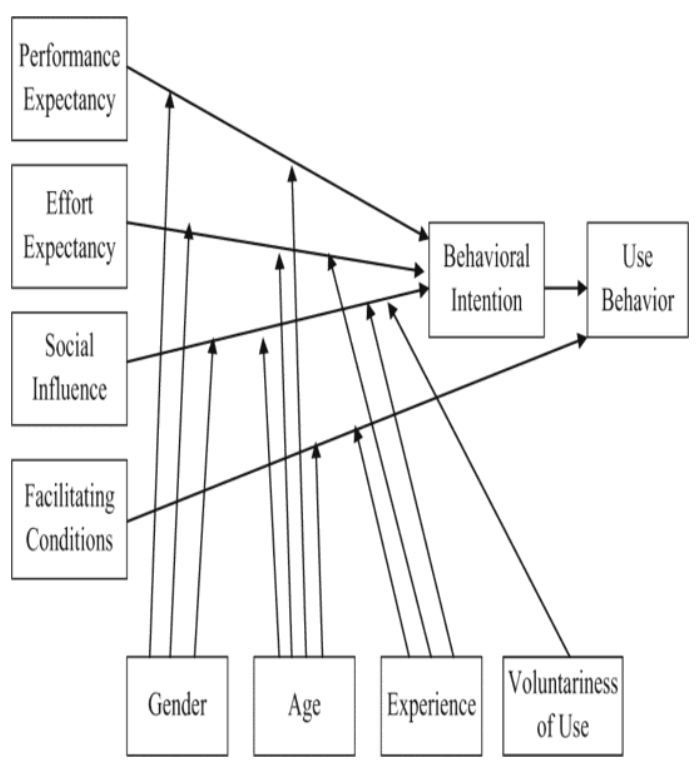

Fig. 1. Unified Theory of Acceptance and Use of Technology [21]

\section{ARCS MODEL}

The ARCS model is based on a synthesis of motivational concepts and its characteristics are considered into four categories: attention (A), relevance (R), confidence (C), and satisfaction (S)" [12]. It is further explained by other researchers such as [13] [14]. Researchers have summarized the dimensions of ARCS model as follows:

- Attention: Emphasis on attracting the attention of learners in several ways, such as variety of videos, lectures and reading.

- Relevance: The importance of using instruction, command and other materials related to what users are familiar with and what they need.

- Confidence: Learners should be given a reward, a chance to succeed and increase the confidence they have.

- Satisfaction

The learner must get practical exercises and tests to increase their satisfaction with learning materials.

In addition, Keller stated that ARCS model "provides guidance for analyzing the motivational characteristics of a group of learners and designing motivational strategies based on this analysis"[11].

\section{STUDY PROBLEM}

Most of the researchers in Cloud Computing system are interested in examining the importance of those applications and their success in maintaining data security, availability, electronic libraries, and online education. Due to early studies, it was found that there is a lack of researches on examining the use of Cloud Computing applications by university students in studying and performing their tasks.
Different dimensions of the model were used in measuring motivation towards acceptance of those applications.

\section{RESEARCH MODEL}

The research model showed in figure 2 measures the acceptance of Cloud Computing Applications and adapted from the work by [21] [12] [23].

This model discusses the effect of the certain factors which are (Performance Expectancy, Effort Expectancy, Attitude toward Using Technology, Social Influence, Self-Efficacy, Attention, Relevance and Anxiety) on the Behavioral Intension of Cloud Computing Applications. The purpose of this model is to examine the impact of the considered factors related to acceptance and motivation on Behavioral Intention to use Cloud Computing Application by university students.

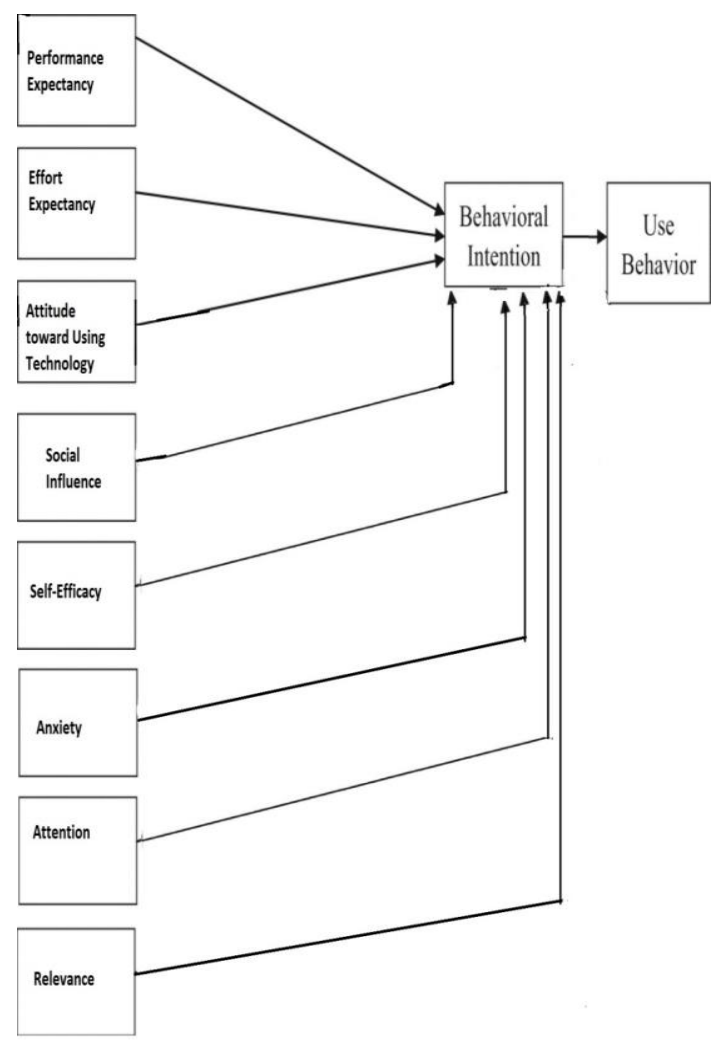

Fig. 2. Research model

\section{RESEARCH HYPOTHESIS}

H0. There is no correlation between Performance Expectancy and Behavioral Intention in Cloud Computing Applications

H1. There is no correlation between Effort Expectancy and Behavioral Intention in Cloud Computing Applications

H2. There is no correlation between Attitude toward Using Technology and Behavioral Intention in Cloud Computing Applications 
H3. There is no correlation between Social Influence and Behavioral Intention in Cloud Computing Applications

H4. There is no correlation between Self-Efficacy and Behavioral Intention in Cloud Computing Applications

H5. There is no correlation between Anxiety and Behavioral Intention in Cloud Computing Applications

H6. There is no correlation between Attention and Behavioral Intention in Cloud Computing Applications

H7. There is no correlation between Relevance and Behavioral Intention in Cloud Computing Applications

\section{METHODOLOGY}

\section{A. Data Collection}

The researcher collected data using the developed survey. The student participated in this study are 110 . They are undergraduate and postgraduate students from different Jordanian universities. This study measures technology acceptance by adopting questions from [21][12] [23].

\section{B. Procedure}

The study uses a mix approach of questionnaire and interview as follows:

- Investigating the dimensions of both the acceptance and motivation models.

- Distributing the questionnaire online to participant.

- Interviewing students to measure their acceptance and satisfaction.

- Analyzing the data using SPSS package.

Different Cloud Computing Applications are examined by this study.

\section{Experimental Group}

The goals of this experiment are to demonstrate the importance of cloud computing in student's homework assignments and to examine the factors affecting students' performance through observation and survey results.

For this purpose, a group of students has created and the analysis of an electronic survey using Form in Google Docs applications has been conducted.

At the first instance some of the students were reluctant to use the Cloud Computing Applications because they were lacking of expertise. With the efforts of the researcher in highlighting the advantages and the benefits of using Cloud Computing Applications and providing some training using Google Docs Applications, the group of the participants was highly motivated to use this technology.
Thus, the participant group has conducted their assignment in an efficient way and achieved better results compared with their colleagues who have not used Cloud Computing Technology.

The experimental group got benefits from using Google Docs Application as follows:

- Creating large number of surveys for free

- Sharing knowledge, ideas and thoughts with large number of participants through a web browser.

- Distributing the surveys globally via URL or an e-mail.

- Collecting responses automatically in MS Excel for easy analysis, charts and functions.

- Helping students in choosing different question types through Google Form.

\section{RESUlTS AND DisCUSSIONS}

\section{A. Descriptive Sample}

The sample of the study consisted of 110 undergraduate and postgraduate students. The findings show that $64.5 \%$ of the respondents are of age 18 to $24,26.4 \%$ of the respondents is of age 25 to $31,5.5 \%$ of the respondents are of age from 31 to 37 and $3.6 \%$ of the respondents are of age 45 or greater. These results are illustrated in figure 3 .

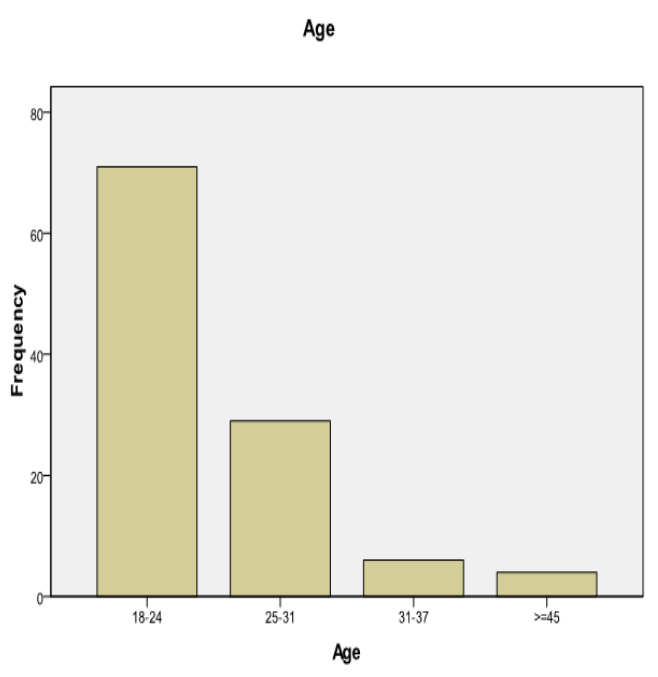

Fig. 3. Distribution of the participants' age

The results in figure 4 show those participants with computer experience which ranging from excellent (27.3\%) to week (1.8) based on Likert scale. 


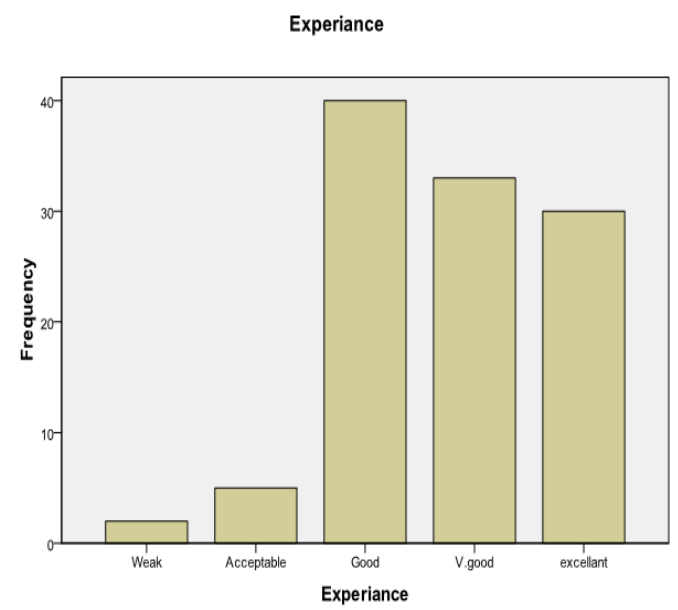

Fig. 4. Distribution of participants' computer experience

\section{B. Statistic}

The findings from the data analysis show the following:

H0. There is a significant relation between Performance Expectancy and Behavioral Intention in Cloud Computing Applications (equal $=0.594$ significant at level 0.01).

H1. There is a significant relation between Effort Expectancy and Behavioral Intention in Cloud Computing Applications (equal $=0.455$ significant at level 0.01).

$\mathrm{H} 2$. There is a significant relation between Attitude toward Using Technology and Behavioral Intention in Cloud Computing Applications (equal $=0.589$ significant at level $0.01)^{\prime}$

H3. There is a significant relation between Social Influence and Behavioral Intention in Cloud Computing Applications (equal $=0.504$ significant at level 0.01).

H4. There is a significant relation between Self-Efficacy and Behavioral Intention in Cloud Computing Applications (equal $=.478$ significant at level 0.01 )

H5. There is a negative relation between Anxiety and Behavioral Intention in Cloud Computing Applications (equal $=-0.121$ significant at level 0.01).

H6. There is a significant relation between Attention and Behavioral Intention in Cloud Computing Applications (equal $=0.642$ significant at level 0.01).

H7. There is a significant relation between Relevance and Behavioral Intention in Cloud Computing Applications (equal $=0.556$ significant at level 0.01).

The results show that the students are able to use Cloud Computing Applications with different levels of knowledge through the questionnaire and observations. It also show that there is a significant relation between Performance Expectancy and Behavioral Intention in Cloud Computing Applications (equal $=0.594$ ). However, it has been found that there is a weak correlation (equal to 0.454) between usefulness and Behavioral Intention of Clouds Computing regarding to the Performance Expectancy.

In addition, the results also show Performance Expectancy, Effort Expectancy, Attitude toward Using Technology, Social Influence, Self-Efficacy, Attention and Relevance have different levels of significant correlation with Behavioral Intention in Cloud Computing Applications with a negative correlation between Anxiety and Behavioral Intention in Cloud Computing Applications. This negative correlation may be due to the students' hesitation of using Cloud Computing Applications. Their anxiety might be caused by the fear of losing information as a result of choosing a wrong option.

Further, the results show that the experimental group has the desire to use Cloud Computing Applications. However, the survey results also show that they have some anxieties toward using Cloud Computing Applications as a result of lack of sufficient knowledge on the benefits of the cloud technology.

The results indicating that there is a motivation toward using a Cloud Computing Applications among students as explained by the significant relation between Attention and Behavioral Intention in Cloud Computing Applications.

One of the benefits of the experimental group in this study is highlighting the need for considering more factors that may have impacts on Behavioral Intention in Cloud Computing Applications. Such factors are those that may affect the use of a Cloud Computing Application in free time, planning to use it in future, and using this technology as often as possible.

\section{CONClusions}

This study finds out that Jordanian university students have the desire, motivation and ability to use Cloud Computing Applications in conducting their study work including homework assignment. However, instructors have to work toward encouraging and educating students on the importance of Cloud Computing Applications and their roles in getting the required information and facilitate the mechanics of completing homework. This would alleviate anxiety due to lack of sufficient knowledge on the benefits of Cloud Computing Applications.

It also concluded that students using Cloud Computing Applications are performing better than those who have not used this technology. The analysis of the results indicates that there is a positive correlation between almost all the considered factors in this study and Behavioral Intention in Cloud Computing Applications.

\section{FUTURE WORK}

This study should be explored to include more students from different countries to have comprehensive results. The study may be expanded by further consideration of the relation between knowledge acceptance and other factors.

Based on the results of this study it is proposed to establish a virtual Cloud Acceptance and Usability Center (CAUC). The purpose of set center is to contains all the research outputs in the different areas of Cloud Computing from different countries to enhance cloud products, make it more usable, and 
obtain comprehensive results and comparative studies among users of Cloud Computing Applications globally.

\section{REFERENCES}

[1] Abid, Muhammad Haris, Tasleem Mustafa and Muhammad Shakeel Faridi , "Cloud Computing: A general user's perceptions and security issues at Universities of Faisalabad Pakistan, " JCSI International Journal of Computer Science Issues, Vol. 9, Issue 5, No 2, 2012.

[2] Abu El-Ala, N. S., W. A. Awad and H. M. El-Bakry," Cloud Computing for Solving E-Learning Problems," IJACSA, International Journal of Advanced Computer Science and Applications, vol. 3, No. 12, 2012, www.ijacsa.thesai.org

[3] Adeoye, Blessing F.,"Utilization of Cloud Computing in education," Journal of global research in computer science, Vol. 6, No. 4, April 2015.

[4] Al Mourad, Mohamed Basel and Mohammed Hussain,"The Impact of Cloud Computing on ITIL Service Strategy Processes," International Journal of Computer and Communication Engineering, vol. 3, No. 5, September 2014.

[5] Attuquayefio, Samuel NiiBoi and Ghana Hillar Addo, "Using the UTAUT model to analyze students' ICT adoption," International Journal of Education and Development using Information and Communication Technology (IJEDICT), vol. 10, Issue 3, pp. 75-86, 2014.

[6] Chung, Hyunji, Jungheum Park, Sangjin Lee, and Cheulhoon Kang,"Digital forensic investigation of cloud storage services," Digital Investigation, vol. 9, Issue 2, PP. 81-95, 2012.

[7] Gorelik, Eugene, "Cloud Computing Models," Working Paper CISL\# 2013-01, Massachusetts Institute of Technology, Master Thesis, 2013.

[8] Hashemi, Sajjad,"Cloud Computing Technology for E-Government Architecture," International Journal in Foundations of Computer Science \& Technology (IJFCST), vol. 3, No.6, November 2013.

[9] Hashemi, Sajjad and Seyyed Yasser Hashemi,"Cloud Computing for ELearning with More Emphasis on Security Issues," World Academy of Science, Engineering and Technology International Journal of Computer, Control, Quantum and Information Engineering, vol.7, No.9, 2013.

[10] Karim, Faten, Robert Goodwin," Using Cloud Computing in E-learning Systems," International Journal of Advanced Research in Computer Science \& Technology (IJARCST), vol. 1, issue 1, 2013

[11] Keller, J. M., Motivational systems. In H. D. Stolovitch, \& E. J. Keeps (Eds.), Handbook of human performance technology, 2nd Edition. San Francisco: Jossey-Bass Inc., Publisher, 1999.
[12] Keller, John," John .How to integrate learner motivation planning into lesson planning: The ARCS model approach," Paper presented at VII Semanario, Santiago, Cuba, 2000.

[13] Malik, Sangeeta," Effectiveness of Arcs Model of Motivational Design to Overcome Completion Rate of Students in Distance Educations," Turkish Online Journal of Distance Education, vol. 15, no.2: Article 14, 2014.

[14] Marshall, James and Matthew Wilson,"Motivating e-Learners: Application of the ARCS Model to e-Learning for San Diego Zoo Global's Animal Care Professionals," The Journal of Applied Instructional Design, Vol. 3, Issue 2, October 2013, www.jaidpub.org

[15] Mell, P., T. Grance, "The NIST Definition of Cloud Computing," Gaithersburg, National Institute of Standards and Technology, 2011.

[16] Padhy, Rabi Prasad, Manas Ranjan Patra and Suresh Chandra Satapathy,"Cloud Computing: Security Issues and Research Challenges," IRACST - International Journal of Computer Science and Information Technology \& Security (IJCSITS) vol. 1, no. 2, December 2011.

[17] Piplode, Rajesh and Umesh Kumar Singh,"Overview and Study of Security Issues \& Challenges in Cloud Computing," International Journal of Advanced Research in Computer Science and Software Engineering Research Paper, vol. 2, issue 9, 2012.

[18] Rizzardini, Rocael Hernez, Linares, Byron, Mikroyannidis, Alexander and Schmitz, Hans-Christian, "Cloud services within a ROLE-enabled Personal Learning Environment," 1st International Workshop on Cloud Education Environments (WCLOUD 2012), Antigua, Guatemala, November 2012.

[19] Stephen, Okeke,"The Study of the Application of Data Encryption Techniques in Cloud Storage to Ensure Stored Data Integrity and Availability," International Journal of Scientific and Research Publications, vol. 4, issue 10, October 2014.

[20] Thomas, Troy Devon, Lenandlar Singh and Kemuel Gaffar, "The utility of the UTAUT model in explaining mobile learning adoption in higher education in Guyana," International Journal of Education and Development using Information and Communication Technology (IJEDICT), vol. 9, issue 3, pp. 71-85, 2013.

[21] Venkatesh, Viswanath, Michael G. Morris, Gordon B. Davis and Fred D. Davis, "User Acceptance of Information Technology: Toward a Unified View," MIS Quarterly, pp. 425-478, 2003.

[22] Vouk, Mladen A.," Cloud Computing - Issues, Research and Implementations," Journal of Computing and Information Technology CIT 16, 4, pp. 235-246, 2008.

[23] Yuvaraj, Mayank,"Examining Libraries' behavioral intention to use cloud computing applications in Indian center universities," Annuals for library and information Studies, vol. 60, pp. 260-268, 2013. 